\title{
Fracture Resistance of CAD/CAM Versus Traditional Interim Fixed Dental Prostheses
}

\author{
DANIEL ALEXANDRU POP1, R. MALAESCU1, LIVIU MARSAVINA², TIBERIU HOSSZU3*, RAUL ROTAR ${ }^{1}$, LUCIANA GOGUTA ${ }^{1}$, \\ VIRGIL FLORIN DUMA ${ }^{2,4}$, MEDA LAVINIA NEGRUTIU ${ }^{1}$, COSMIN SINESCU ${ }^{1}$, ANCA JIVANESCU ${ }^{1}$ \\ ${ }^{1}$ Victor Babes University of Medicine and Pharmacy, Faculty of Dental Medicine, 2 Eftimie Murgu Sq., 300041 Timisoara, Romania \\ ${ }^{2}$ Polytechnic University of Timisoara, Faculty of Mechanical Engineering, 1 Mihai Viteazu Blvd., 300006, Timisoara, Romania \\ ${ }^{3}$ Vasile Goldis Western University of Arad, 94 Revolutiei Av., 310025 Arad, Romania \\ ${ }^{4}$ Aurel Vlaicu University of Arad, Faculty of Engineering, 30M Optomechatronics Group, 77 Revolutiei Av., 310130 Arad, Romania
}

The aim of this in vitro study is to compare the load-to-fracture performance of polymethyl methacrylates (PMMA) provisional restorations manufactured with a traditional laboratory technique in comparison to a computer-assisted design and computer-assisted manufacturing (CAD-CAM) technique. Five interim threeunit fixed dental prostheses were fabricated with the conventional indirect technique, on a standard typodont. The same model was scanned with an intraoral scanner and the digital design of identical fixed dental prostheses was made. Then other five interim three-unit fixed dental prostheses were milled from PMMA CAD/CAM blocks with an in office milling machine. All specimens were tested for flexural strength in a universal testing machine, and the maximum load to fracture was measured. For the conventional provisional restorations, the load to fracture was $121.16 \pm 24.6$, in comparison to CAD/CAM interim restorations, for which the load to fracture was $728.88 \pm 228.7$. Within the limitations of this study, one can conclude that CAD/CAM provisional restorations present a higher fracture load than the conventional manufactured interim restorations.

Keywords: interim restorations, polymethyl methacrilat(PMMA), computer-assisted design (CAD), computerassisted manufacturing (CAM), load to fracture

Provisional restorations can be manufactured from different materials. They have several necessary characteristics, such as the protection of the pulp and of the periodontal tissues, as well as the marginal and occlusal stability. Nowadays, the role of provisional restorations also consists of a proper evaluation of the function, the aesthetics, and the phonetics. Interim fixed dental prostheses musthave colour stability and resistance in order to be maintained for a longer period of time [1].

In the last decade, an increasing number of computerassisted design and computer-assisted manufacturing (CAD/CAM) systems are utilized for the manufacturing of single crowns, as well as of fixed dental prostheses in the dental practice [2-4].

CAD/CAM systems are composed of three major parts: (i) a data acquisition unit or scanner, which collects the data from the region of the prepared teeth and neighbouring structures and then converts them to virtual impressions; (ii) the design software for designing virtual restorations and setting-up all the milling parameters; (iii) the processing device or a computerized milling machine to manufacture the restoration from solid blocks of the chosen restorative material [4].

The fit and the resistance are considered as criteria for the long-term success of CAD/CAM restorations. An example of a material capable to perform CAD/CAM interim restorative is Telio CAD (Ivoclar Vivadent AG). This composite resin is a cross-linked Polymethyl methacrylate (PMMA) block, but unlike conventional PMMA materials, has more homogeneity and strength [5]. It has certain interesting properties: it does not undergo polymerization shrinkage; it does not have an inhibitor layer; it is polymerized under standardized parameters at high temperature and pressure in order to ensure a constant quality before milling; itcan be used for fabricating interim crowns and partial fixed dental prostheses [6-7].

The purpose of this study is to compare the flexural strength of three-unit interim fixed dental prostheses manufactured with a conventional technique and with a CAD/CAM technology.

\section{Experimental part}

Material and methods

Using a standard typodont, the lower second premolar was removed in order to simulate a class III Kennedy edentulous space, and the first molar and premolar were prepared with a supra-gingival finish line (fig. 1). Next, provisional restorations were manufactured using the two considered techniques, with the conventional/classical indirect technique (in the dental laboratory), and using the digital technique with chair side CAD/CAM technology.

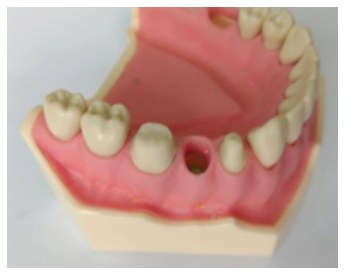

Fig. 1. The abutment preparation on the typodont.

For the classical technique, five conventional impressions were taken using polyvinyl siloxane in two consistencies and then pouring them in dental stone. On the stone models, 5 provisional fixed dental prostheses were fabricated in the dental laboratory using acrylic resin (PMMA) (fig. 2).

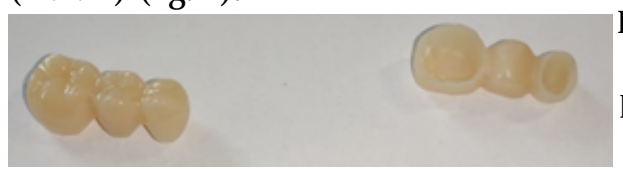

Fig. 2. Provisional fixed dental prostheses made in the dental laboratory 
For the CAD/CAM technique, a digital impression was taken using an intraoral scanner PlanScan (Planmeca OY, Helsinki, Finland) and the digital model was obtained - Fig. 3(a). In order to obtain identical provisional restorations, a pre-op digital impression was taken with the indirect provisional restorations in place, onto the typodont. After easily performing the design with the software Plan CAD, it was exported to the milling machine. The material used for the CAD/CAD provisional fixed dental prostheses was Telio CAD, a PMMA block for milling (fig. 3(b)). Five blocks were milled, obtaining five CAD/CAM provisional restorations.

(a)
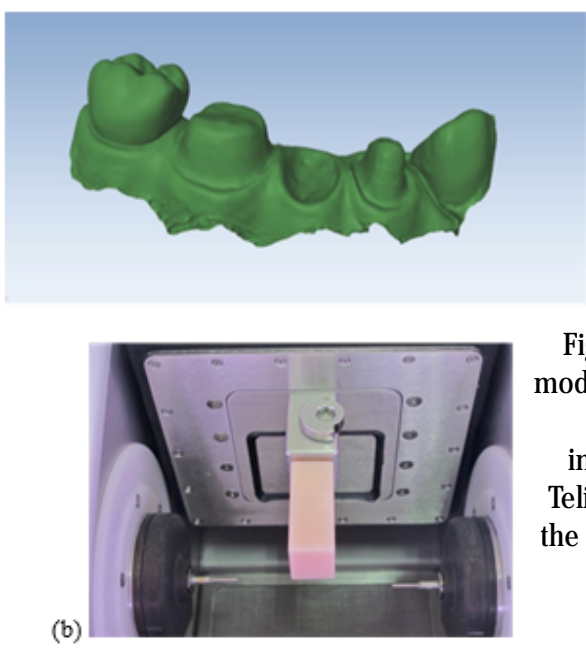

Fig. 3. (a) Digital model obtained after the digital impression; (b) Telio CAD block in the milling machine

Next the provisional restorations were tested for flexural strength and fracture load, using an universal testing machine Zwick Proline Z 005 (Kennesaw, GA, USA), i.e. a pressure was applied on the occlusal surface until failure. The applied load was concentrated in the middle of the provisional and with a loading speed of $1 \mathrm{~mm} / \mathrm{min}$ at room temperature (fig. 4).

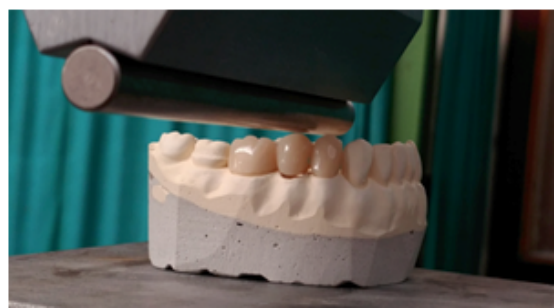

Fig. 4. Provisional restorations under load applied with a hydraulic press

\section{Results and discussions}

All values were analyzed using a statistic software, MedCalc (MedCalc Software, Ostend, Belgium). The Kolmogorov-Smirnov test was used to assess data distribution, while statistical differences between test groups were analyzed using the $t$ test. The values for each provisional restoration are presented in table 1.

For the conventional provisional restorations the maximum force applied was $152.6 \mathrm{~N}$, with a sample deformation of $0.59 \mathrm{~mm}$ (fig. 5(a)). Regarding the CAD/ CAM restorations, force values were considerably higher, with a maximum load of $915 \mathrm{~N}$ ( fig. 5(b)).

Statistically significant differences appear among the test groups, with a $p$ value of $0.0018(p<0.05)$.

The overall mean force values showed that the CAD/ CAM provisional restorations had the highest load resistance with a mean value of $728.88 \mathrm{~N}$, while the conventional provisional restorations had a mean value of $121.16 \mathrm{~N}$.

All conventional provisional restorations had the same fracture location, at the interface between the second premolar and the first molar, in the pontic region. The fracture location for the CAD/CAM provisional restorations was in the middle of the second premolar.
Table 1

FRACTURE FORCE AND MAXIMUM DEFORMATION FOR EACH SAMPLE

\begin{tabular}{|c|c|c|c|c|}
\hline $\begin{array}{l}\text { Manufacturing } \\
\text { technique }\end{array}$ & Sample & $\begin{array}{l}\text { Fracture } \\
\text { force }[N]\end{array}$ & $\begin{array}{l}\text { Maximum } \\
\text { deformation } \\
\text { [mm] }\end{array}$ & $\begin{array}{l}\text { Mean } \\
\text { fracture } \\
\text { force [N] }\end{array}$ \\
\hline \multirow{5}{*}{$\begin{array}{l}\text { Traditional } \\
\text { laboratory } \\
\text { technique }\end{array}$} & 1 & 122.00 & 0.75 & \multirow{5}{*}{$\begin{array}{l}121.16 \pm \\
24.6\end{array}$} \\
\hline & 2 & 93.80 & 0.69 & \\
\hline & 3 & 100.30 & 0.71 & \\
\hline & 4 & 137.10 & 0.77 & \\
\hline & 5 & 152.60 & 0.59 & \\
\hline \multirow{5}{*}{$\begin{array}{l}\mathrm{CAD} / \mathrm{CAM} \\
\text { technique }\end{array}$} & 1 & 894 & 1.58 & \multirow{5}{*}{$\begin{array}{l}728.88= \\
228.7\end{array}$} \\
\hline & 2 & 915 & 1.90 & \\
\hline & 3 & 732.6 & 1.51 & \\
\hline & 4 & 756.8 & 1.54 & \\
\hline & 5 & 346 & 1.74 & \\
\hline
\end{tabular}
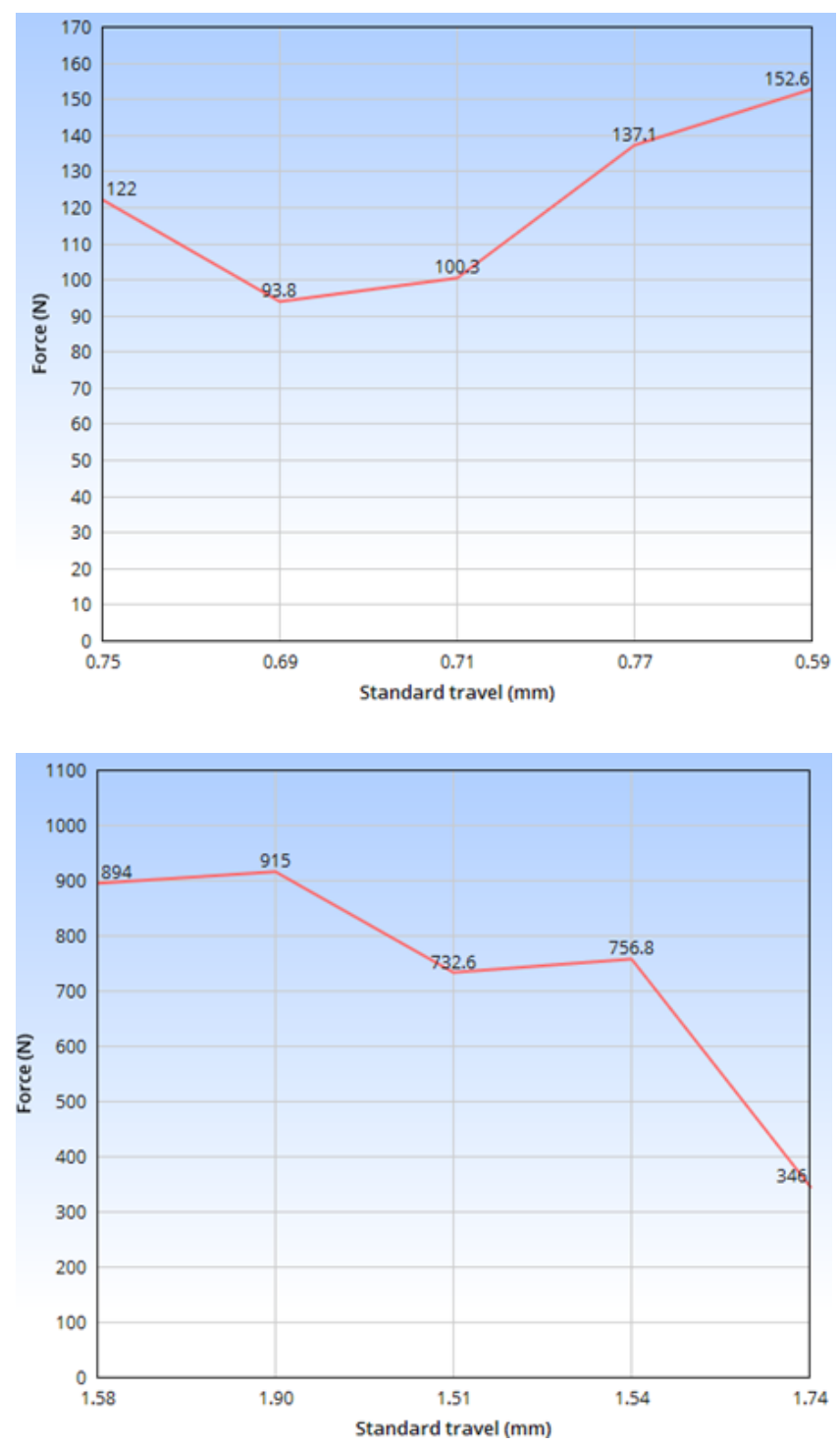

Fig. 5. (a) Flexural strength of provisional restorations fabricated with traditional dental laboratory; (b) chair-side CAD/CAM technique 
Fig. 6. Fracture pattern of CAD/CAM provisional restorations at higher load

Provisional restorations are still the focus point of many in vitro tests, as well as in vivo cases. As new materials appear, the premises for long lasting interim restorations which allow for more predictable treatments increase as well.

A number of studies showed the superior mechanical properties of CAD/CAM manufactured provisional restorations compared to their laboratory counterpart. Edelhoff et al. evaluated the fracture strength of three unit CAD/CAM provisional restorations, compared to traditional provisional restorations. The results of the study showed increased mechanical properties for the CAD/CAM group [6]. Another study (Balkenhol etal.) investigated differences between interim restorations fabricated with CAD/CAM versus the direct technique (manufactured in the dental office), and concluded that CAD/CAM provisional restorations had much higher fracture resistance [7].

Rayyan compared PMMA CAD/CAM provisional restorations with laboratory manufactured from thermoplastic resins provisional restorations. The results showed less water, less wear, higher surface strength, and higher fracture point for the CAD/CAM restorations [8]. Stawarczyk et al, investigated the fracture resistance of three unit provisional restorations in three scenarios: immediately after fabrication, submerged in artificial saliva and after simulated masticatory forces. The results of their study showed that none of the factors tested influenced the fracture strength of CAD/CAM provisional restorations [9].

CAD CAM applications in digital aligners and the biocompatibility of orthodontic materials have been previously studied in [12-14].

A study that compared the flexural strength of provisional restorations with and without glass fibre reinforcement demonstrated that the reinforcement with glass fibre between the abutments gave the higher flexural strength of the provisional restorations [10]. Another study revealed that no differences were found between the fracture strengths of interim fixed dental prostheses manufactured with a CAD/CAM system and those reinforced with glass fibre [11].

The present study compared the flexural strength and fracture load of two different types of provisional restorations, manufactured with traditional and digital technology from the same class of materials. The results of this study showed a significant statistical difference between PMMA provisional restorations fabricated with CAD/CAM technique when compared to the dental laboratory traditional technique. Another difference between the two groups was related to the fracture location: the laboratory provisional restorations were fractured between the second premolar and the first molar, while the CAD/CAM provisional restorations were fractured on the middle of the second premolar.

\section{Conclusions}

With the limitations of this study (small sample size and absence of simulated forces), one may conclude that $\mathrm{CAD} / \mathrm{CAM}$ provisional restorations presenta higher fracture load, as well as a higher flexural strength than the conventional manufactured counterparts.

Acknowledgements: This work was supported by the Romanian National Authority for Scientific Research, CNDI-UEFISCDI Project PN-III-P2-2.1BG-2016-0297. Cosmin Sinescu also acknowledges the support of the Victor Babes University of Medicine and Phamacy of Timisoara (Grant PIII-C2-PCFI (2015-2016), DENTALOCT).

\section{References}

1.GEGAUFF, A.G., HOLLOWAY, .A., Interim fixed restorations. In: Rosenstiel SF, Land MF, Fujimoto J, editors. Contemporary fixed prosthodontics, 5th ed. St. Louis: Mosby/Elsevier; 2016. p. 401-39.

2.MIYAZAKI, T., HOTTA, Y., CAD/CAM systems available for the fabrication of crown and bridge restorations. Aust Dent J. 2011, 56(1), 97-106.

3.LOGOZZO, S., FRANCESCHINI, G., KILPELA, A.,CAPONI, M., GOVERNI, L. BLOIS,L., A comparative analysis of intraoral 3D digital scanners for restorative dentistry, Internet J. Med. Tech. 2011, 5(1). 4.SCOTTI, R., CARDELLI, P. BALDISSARA, P., MONACO,C., Clinical fitting of CAD/CAM zirconia single crowns generated from digital intraoral impressions based on active wavefront sampling, J. Dent. 2011.

5.BEUER, F., SCHWEIGER, J., EDELHOFF,D., Digital dentistry: an overview of recent developments for CAD/CAM generated restorations, Br. Dent. J. 2008, 204(9), 505-511.

6.EDELHOFF, D., BEUER, F., SCHWEIGER, J.,. BRIXO, O., STIMMELMAYR, M., J., GUTH,F., CAD/ CAM-generated high-density polymer restorations for the pretreatment of complex cases: a case report, Quint. Int. 2012, 43, 457-467.

7.BALKENHOL, M. KNAPP, M., FERGER, P., HEUN, U., WOSTMANN,P., Correlation between polymerization shrinkage and marginal fit of temporary crowns, Dent. Mater. 2008, 24, 1575-1384.

8.RAYYAN, M.M., ABOUSHELIB, M., SAYED, N.M., IBRAHIM, A., JIMBO,R., Comparison of interim restorations fabricated by CAD/ CAM with those fabricated manually, J. Prosthet. Dent. 2015, 114(3), 414-419.

9.STAWARCZYK, B.,ENDER, A.,TROTTMANN, A. OZCAN, M., FISCHER, J., C., HAMMERLE,H., Load-bearing capacity of CAD/CAM milled polymeric three-unit fixed dental prostheses: effect of aging regimens, Clin. Oral Investig. 2012, 16(6), 1669-1677.

10.J IVANESCU, A., HRELESCU, D., GOGUTA, L.,PARVULESCU,L.F., Comparative in vitro study of the flexural strength of resin provisional fixed partial dentures, with and without glass fiber reinforcement, Mat. Plast. 53, no.3, 2016, p. 481

11.PENATE, L., BASILIO, J., ROIG, M., MERCADE,M., Comparative study of interim materials for direct fixed dental prostheses and their fabrication with CAD/CAM technique, J. Prosthet. Dent. 2015, 114, 248253.

12.SZUHANEK, C., JIANU, R., CIRCIUMARU, L., NEGRUTIU,M., SINESCU,C., CLONDA,C.S., SCHILLER, E., POPA, A., GRIGORE, A.,Microstructural Changes in Orthodontic Archwires after Alternative Bending Techniques. Rev. Chim.(Bucharest), 67, no11, 2016, p.23632364.

13.SZUHANEK, C., GRIGORE,A., Determination of microelements from orthodontic implants by the flame atomic absorption spectroscopy method. Rev. Chim.(Bucharest), 66, no.10, 2015 p.1600-1602,

14. SZUHANEK, C., GRIGORE, A., BRATU, D.C., ONISEI, D., The role of digital setup in the orthodontic treatment with plastic aligners. Mat. Plast., 52, no. 4, 2015.

$\overline{\text { Manuscript received:17.05.2018 }}$ 